\title{
West Syndrome Secondary to Biotinidase Deficiency about a Case
}

\section{Madiha Abouelarais' ${ }^{1}$, Nour Mekaoui ${ }^{1}$, Fatima Zohra Oudghiri' ${ }^{1}$, Khaoula Mammad ${ }^{2}$, Lamia Karboubi', Badr Sououd Benjelloun Dakhama1}

${ }^{1}$ Pediatric Medical Emergency Department, Rabat Children's Hospital, University Hospital of Ibn Sina, Faculty of Medicine and Pharmacy, Mohammed V University, Rabat, Morocco

${ }^{2}$ Unit of Neuroscience and Applied Nutrition, Laboratory of Nutrition, Health and Environment, Department of Biology, Faculty of Science, Kenitra, Morocco

Email: madiha182@hotmail.com

How to cite this paper: Abouelarais, M., Mekaoui, N., Oudghiri, F.Z., Mammad, K., Karboubi, L. and Dakhama, B.S.B. (2017) West Syndrome Secondary to Biotinidase Deficiency about a Case. Neuroscience \& Medicine, 8, 29-32.

https://doi.org/10.4236/nm.2017.83004

Received: August 28, 2017

Accepted: September 25, 2017

Published: September 28, 2017

Copyright (C) 2017 by authors and Scientific Research Publishing Inc. This work is licensed under the Creative Commons Attribution International License (CC BY 4.0).

http://creativecommons.org/licenses/by/4.0/

\begin{abstract}
Biotinidase deficiency is an abnormality of biotin metabolism which is manifested by neurological, cutaneous, ophthalmological and auditory signs. It has been described as a cause of West syndrome, but there are few observations that report an association between these latter two. We report the observation of an 18-month old infant born from a first-degree consanguineous marriage, followed since the age of 2 months and half for West syndrome associated with alopecia, also an eczema and deafness in whom the etiological investigation was in favor of a biotinidase deficiency. Thus treatment with biotin resulted in a marked clinical improvement.
\end{abstract}

\section{Keywords}

West Syndrome Secondary, One Case, Biotinidase Defiency

\section{Introduction}

The biotinidase deficiency is an autosomal recessive hereditary abnormality, and biotin metabolism, resulting in the inability to recycle biotin from its dietary and endogenous sources [1]. It is due to mutations in the BTD gene of biotin metabolism, this disorder, if untreated, can affect many parts of the body and cause delayed development. While the incidence is estimated at $1 / 60,000$ newborns [2], the clinical manifestations usually appear between the $2^{\text {nd }}$ and $5^{\text {th }}$ month of life, and a convulsions are almost constant and begin within the first 3 months of life.

The clinical features that should guide the diagnosis are the presence of severe atopic dermatitis, alopecia, deafness, optic atrophy and deep hypotonia espe- 
cially if the treatment is delayed. In addition, early screening is possible and allows for early treatment and avoids irreversible sequelae: auditory and visual cognition.

\section{Observation}

It is an 18-month old female infant born from a first-degree consanguineous marriage, unique to her parents, without any notion of neonatal distress which has had spasms in flexion with hypotonia since the age of 10 weeks. The parents gave their consent to report their child's clinical observation. Otherwise Clinical examination had shown a hypotonic infant, absence of ocular tracking and reaction to noises, generalized eczema and alopecia. The cranial perimeter and weight were normal, and the electroencephalogram had shown hypsarrhythmia, and the auditory evoked potentials had revealed deafness.

The rest of the para-clinical examination was unremarkable, namely cerebral MRI and metabolic assessment (ammonia, lactatemia, chromatography of amino acids in blood and urine, and study of cerebrospinal fluid), and the infant was initially under vigabatrin without improvement. Also, the evolution was marked by the persistence of the spasms in flexion, and the appearance of a psychomotor retardation.

Given the clinical picture (epileptic encephalopathy, hypotonia, eczema, alopecia, deafness and probable blindness) and non-improvement under vigabatrin, the diagnosis of biotinidase deficiency was retained even in the absence of a dosage of the latter. However, the infant was placed under biotin, after a 14-month follow-up, there was a marked regression of convulsive seizures, an acquisition of the seated position and roughing of the step, an improvement in eczema and alopecia. He is a candidate for cochlear implantation.

\section{Discussion}

The biotin cycle is involved in many metabolic pathways (amino acid catabolism, fatty acid synthesis, and gluconeogenesis). The biotinidase deficiency can also cause a malfunction of this cycle and is responsible for a decrease in the biotin recycling from its dietary and endogenous sources and the accumulation of different metabolites in the urine which results in severe encephalopathy with epilepsy. The incidence is $1 / 60,000$ newborns born in Western countries, 1/14,800 newborns born in Turki [3], this high incidence in Turki was explained by the high frequency of consanguineous marriages. The age of onset of symptoms varies from one week to two years with an average of 5.7 months, while female predominance has been reported in the literature (17 girls versus 13 boys in the Wolf 1985 series [4]).

The clinical picture associates neurological, cutaneous, ophthalmological and auditory signs. Dermatological manifestations are dominated by alopecia and eczema (atopic or seborrheic eczema), convulsions are the common symptom of biotinidase deficiency and are the main neurological manifestation, they are 
present in $70 \%$ of cases [4]. These convulsions are generally myoclonic [5].

In the series of Venkataraman et al. [6] involving seven children with biotinidase deficiency, the seizures were in the majority of cases clonic. Other neurological manifestations include hypotonia, psychomotor retardation, ataxia, optic atrophy, deafness and paraparesis, in our patient, the neurological expression was represented by a syndrome of West with the triad: spasms in flexion, retardation of the psychomotor development and hypsarrhythmia.

Diagnostic confirmation is based on the enzymatic determination of biotinidase [1] [7], in our case the diagnosis has been oriented by the association of epileptic encephalopathy resistant to antiepileptic drugs, hypotonia, dermatological signs (alopecia, eczema) and deafness.

The treatment is based on biotin supplementation (10 to $20 \mathrm{mg}$ per day) which can be established as a therapeutic test in front of an evocative clinical picture. The clinical evolution under biotin is spectacular with regression of the convulsions and improvement of the dermatological signs, and deafness and optic atrophy are irreversible [4].

Through this observation, the authors insist on the interest of suspecting the diagnosis of biotinidase deficiency in front of a table associating convulsions with other neurological (hypotonic) and dermatological manifestations (eczema, seborrheic dermatitis, alopecia) and to treat by biotin even in the absence of biological confirmation, because the prognosis depends on the precocity of initiation of treatment (note that deafness and optic atrophy are irreversible).

\section{Conclusion}

Lastly, the deficiency in biotinidase is a pathology which is not uncommon, to which one must think before the association of neurological signs, dermatological manifestations, deafness and optical atrophy. Treatment is easy and can be started even in the absence of biological confirmation to avoid irreversible sequelae.

\section{References}

[1] Wolf, B. (2012) Biotinidase Deficiency: If You Have to Have an Inherited Metabolic Disease, This Is the One to Have. Genetics in Medicine, 14, 565-575. https://doi.org/10.1038/gim.2011.6

[2] Wolf, B. (1991) Worldwide Survey of Neonatal Screening of Biotinidase Deficiency. Journal of Inherited Metabolic Disease, 14, 923-937. https://doi.org/10.1007/BF01800475

[3] Komur, M., Okuyaz, C., et al. (2011) A Girl with Spastic Tetraparesis Associated with Biotinidase Deficiency. European Journal of Pediatric Neurology, 15, 551-553. https://doi.org/10.1016/j.ejpn.2011.04.012

[4] Wolf, B. (1985) Biotinidase Deficiency: Initial Clinical Features and Rapid Diagnosis. Annals of Neurology, 18, 614-617. https://doi.org/10.1002/ana.410180517

[5] Salbert, B.A., Pellock, J.M. and Wolf, B. (1993) Characterization of Seizures Associated with Biotinidase Deficiency. Neurology, 43, 1351-1355. 
https://doi.org/10.1212/WNL.43.7.1351

[6] Venkataraman, V., Balaji, P., et al. (2013) Biotinidase Deficiency in Childhood. Neurology India, 61, 411-413. https://doi.org/10.4103/0028-3886.117614

[7] Wolf, B. (2010) Clinical Issues and Frequent Questions about Biotinidase Deficiency. Molecular Genetics and Metabolism, 100, 6-13.

https://doi.org/10.1016/j.ymgme.2010.01.003

Submit or recommend next manuscript to SCIRP and we will provide best service for you:

Accepting pre-submission inquiries through Email, Facebook, LinkedIn, Twitter, etc. A wide selection of journals (inclusive of 9 subjects, more than 200 journals) Providing 24-hour high-quality service User-friendly online submission system Fair and swift peer-review system Efficient typesetting and proofreading procedure Display of the result of downloads and visits, as well as the number of cited articles Maximum dissemination of your research work

Submit your manuscript at: http://papersubmission.scirp.org/ Or contact nm@scirp.org 